\title{
Effects of the Water and Sediment Discharge Regulation Project on Zooplankton in the Yellow River Estuary
}

\author{
Xiuxia Wang ${ }^{1, a}$, Fan $\mathrm{Li}^{1, \mathrm{~b}}$, Yingjie Yue ${ }^{2, \mathrm{c} *}$ and Mingyi Song ${ }^{3, \mathrm{~d}}$ \\ ${ }^{1}$ Shandong Provincial Key Laboratory of Restoration for Marine Ecology, Shandong Marine \\ Resource and Environment Research Institute, Yantai, Shandong, China \\ ${ }^{2}$ Aquatic Design Institute of Shandong Province, Jinan, Shandong, China \\ ${ }^{3}$ Dajijia Sub-district Office, Yantai Economy Technology Development Zone, Shandong, China \\ axiuxia.888@163.com, ${ }^{b} 18153518186 @ 126 . c o m,{ }^{c} 15264526058 @ 163 . c o m$, \\ dytkfqsmy@yahoo.com.cn \\ ${ }^{*}$ Corresponding author
}

Keywords: Zooplankton; Spatiotemporal distribution; The water and sediment discharge regulation project; The Yellow River estuary

\begin{abstract}
The water and sediment discharge regulation (WSDR) project of the Yellow River is yearly implemented from 2002, while there are few reports about its influence on zooplankton. In this paper, we studied the species constitutions, horizontal distribution and community diversity of zooplankton based on the samples collected at 18 sampling stations in the Yellow River estuary in 2014, to compare zooplankton alterations before and after the WSDR project. Phytoplankton, swimming animal and environment variables were investigated simultaneously. RELATE modules of BIOENV in software Primer 6.0 were used to seek the best matches of environmental factors that affect distribution of zooplankton. The results showed that: Species of zooplankton increased while the quantity reduced during WSDR project due to the large reduction in the number of Noctiluca miliaris. Zooplankton community structure became more stable. According to the results of BIOENV analysis, phytoplankton abundance, water depth and inorganic salts had stronger effects on the horizontal distributions of zooplankton.
\end{abstract}

\section{Introduction}

The Yellow River estuary is located at the intersection between Bohai Bay and Laizhou Bay, and is an important spawning ground, feeding ground and rearing ground for marine organisms because of the abundant food supply [1]. The water and sediment discharge regulation (WSDR) project is yearly implemented from 2002 in the Yellow River, designed to scour river channel through artificial flood peak that will transport more than one-third of the annual sediment into the sea in less than a month to realize the effect of sedimentation reduction at downstream river and scouring across the board [2].The water and sediment discharge regulation project has a direct effect on annual runoff distribution of the Yellow River, in addition, the sharp increase of fresh water, nutrients and sediment in a short time has a great impact on ecological environment and biological resources in the Yellow River estuary [3-5]. Marine zooplankton is a major component of marine secondary production and plays an important role in the marine ecosystem with the characteristics of diverse species, abundant quantity and wide distribution [6, 7].In this paper, we research the characteristics of zooplankton community structure before, during and after the WSDR project, to provide basic data for the study of marine ecosystem protection in the Yellow River estuary.

\section{Materials and Methods}

Survey Area and Sample Collection. We conducted three marine surveys in the Yellow River estuary in 2014, that before (June 17-19), during (July 4-7) and after (July 18-21) the water and sediment discharge regulation (WSDR) project respectively. Based on the distance to the Yellow 
River estuary ,eighteen sampled stations were divided into four sections, which distributed between $37^{\circ} 40^{\prime} \mathrm{N}-38^{\circ} 10^{\prime} \mathrm{N}, 118^{\circ} 55^{\prime} \mathrm{E}-119^{\circ} 35^{\prime} \mathrm{E}$ (Fig. 1) .

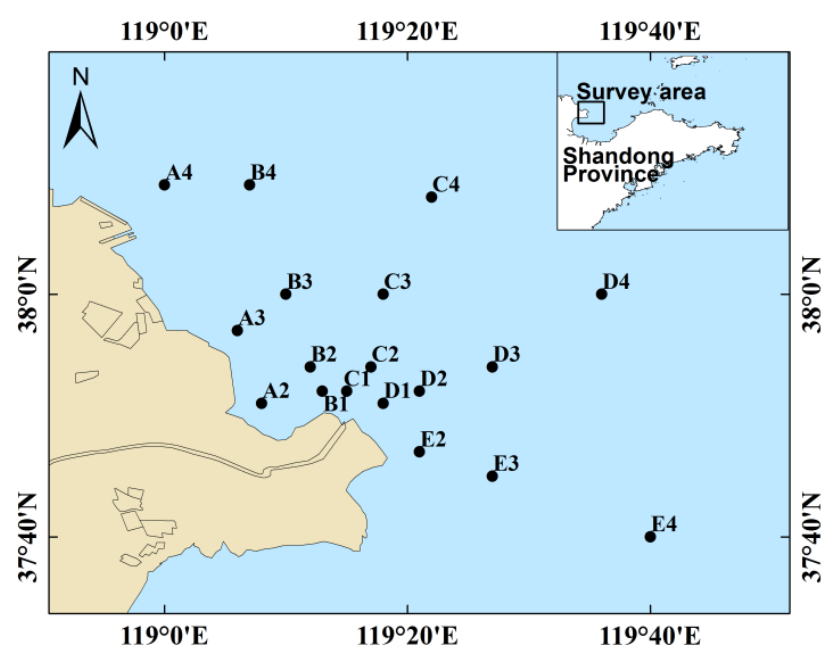

Figure 1. The map of the survey area and sampled stations

Dynamic distributions of the species in the Yellow River estuary were studied based on the zooplankton samples that were collected vertically from bottom to surface by a net with $50 \mathrm{~cm}$ diameter and 505 micron mesh size. Zooplankton samples were saved in 5\% seawater of formaldehyde after collection and analyzed in laboratory. Phytoplankton, swimming animal and the environment variables including TEM(Temperature), SAL(Salinity), DEP(Depth), pH, Chl-a(Chlorophyll a), SS(Suspended solids) ,DO (Dissolved oxygen),COD(Chemical oxygen demand), TN(Total nitrogen), TP(Total phosphorus), $\mathrm{SiO}_{3}{ }^{2-}-\mathrm{Si}$ (Silicate), DIP (Active phosphate), DIN (Inorganic nitrogen) $\left[\mathrm{NO}_{3}{ }^{-} \mathrm{N}, \mathrm{NO}_{2}{ }^{-} \mathrm{N}\right.$ and $\left.\mathrm{NH}_{4}{ }^{+}-\mathrm{N}\right]$ were collected simultaneously. Sampling method at the sea and analyzing method in the laboratory were implemented according to Ocean survey standard. (GB / T12763.9-2007). Zooplankton samples were identified and counted using Olympus SZ51 stereo microscope. Abundance of zooplankton was expressed in number of individuals per cubic meter (ind / $\mathrm{m}^{3}$ ).

Data Analysis. According to zooplankton community characteristics in the Yellow River estuary, the following indexs were used to analyze community diversity [8-10].

Eq. 1 was Marglef species richness index $(d)$.

$d=(S-1) / \log _{2} N$

Eq. 2 was Shannon-Wiener diversity index $\left(H^{\prime}\right)$.

$H^{\prime}=-\sum_{i=1}^{S} P i \log _{2} P i$

Eq. 3 was Pielou uniformity index $\left(J^{\prime}\right)$.

$J^{\prime}=H^{\prime} / \log _{2} S$

$S$ was the number of zooplankton species in the sample; $N$ was the total number of zooplankton individuals; $P i$ was the ratio of the $\mathrm{i}$-th specie number to the total number of zooplankton. Series of multivariate statistical analysis were processed applying PRIMER6.0 software package [11].

\section{Result and Discussion}

Species Composition and Quantity Variation. There were 41 species of zooplankton during and after the water and sediment discharge regulation project respectively, however only 30 species before the water and sediment discharge regulation project. Copepods, zooplankton larvae and jellyfish accounted for an important part. 
Zooplankton abundance showed a decreasing trend, the average abundance of zooplankton was $49034.44 \mathrm{ind} / \mathrm{m}^{3}, 3121.94 \mathrm{ind} / \mathrm{m}^{3}$ and $195.67 \mathrm{ind} / \mathrm{m}^{3}$ in all three surveys respectively. The significant decrease of zooplankton quantity was caused by Noctiluca miliaris that accounted for $99.62 \%$ of the total number of zooplankton before the water and sediment discharge regulation project and then disappeared gradually. Noctiluca miliaris could swallow any zooplankton the size of copepod larvae. The results showed that the suitable temperature for Noctiluca miliaris was between $12 \sim 27^{\circ} \mathrm{C}$ and the suitable salt range was 25 30[12]. With the sudden influx of fresh water during the water and sediment discharge regulation project, salinity and diaphaneity decreased significantly at the Yellow River estuary nearshore stations, which might result in the decline of Noctiluca miliaris quantity.

Horizontal Distribution. As shown in Fig. 2, horizontal distribution of zooplankton was uneven before the water and sediment discharge regulation project. The highest abundance reached $256725.00 \mathrm{ind} / \mathrm{m}^{3}$, which located at A2 station in dense region north of the Yellow River estuary. The sparse region was in the east of the Yellow River estuary, the lowest abundance was only 22.50 $\mathrm{ind} / \mathrm{m}^{3}$ located at E4 station. Concentrated area of zooplankton located in coastal waters might due to the distribution of Noctiluca miliaris which mainly existed in coastal waters [13,14]. Zooplankton abundance reduced during water and sediment discharge regulation project, but the distribution trend did not change. Zooplankton distribution was relatively uniform because Noctiluca miliaris disappeared after the water and sediment discharge regulation project, the lowest density $\left(42.14 \mathrm{ind} / \mathrm{m}^{3}\right)$ was still at E4 station, but the highest density $\left(394.5 \mathrm{ind} / \mathrm{m}^{3}\right)$ changed into B1 station.
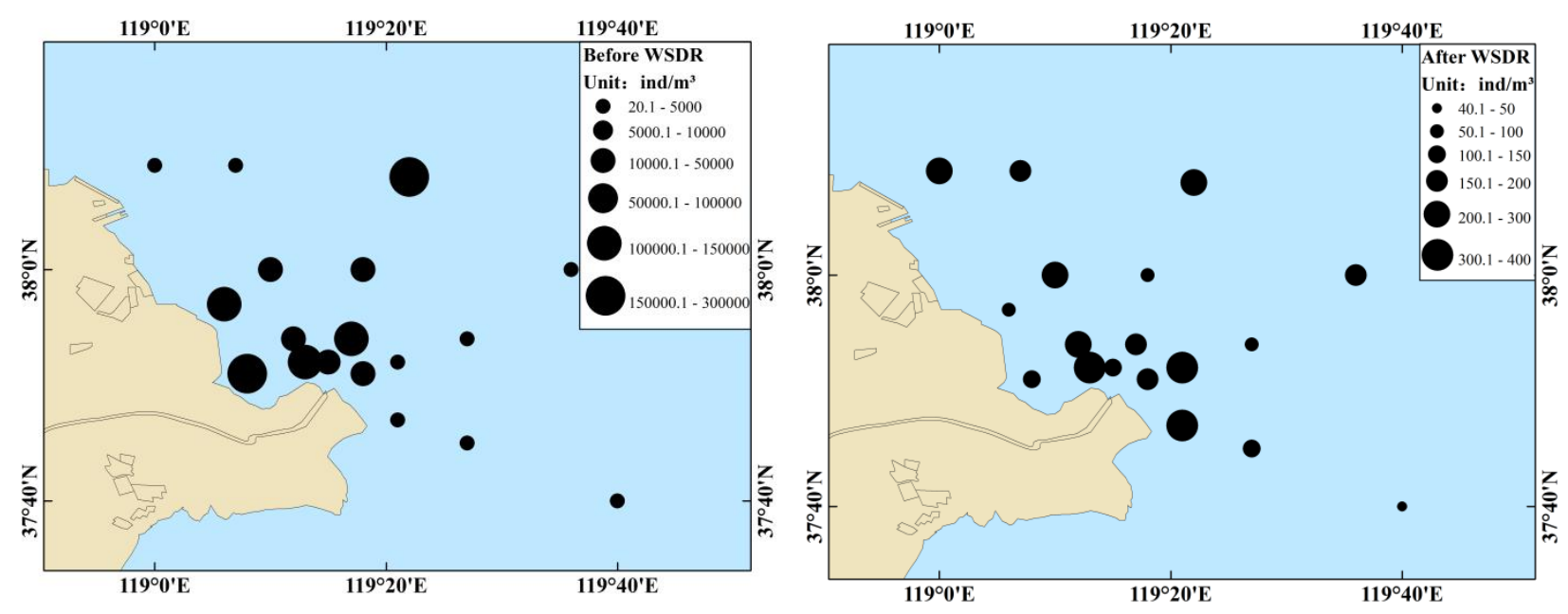

Figure 2. Horizontal distribution of zooplankton abundance (ind $/ \mathrm{m} 3$ ) in the Yellow River estuary before and after the water and sediment discharge regulation (WSDR) project in 2014

Community Index. Zooplankton community indexes had large change in scope between different stations, but they showed increasing trends during three investigations (Fig. 3). The average species richness indexes $(d)$ of the three surveys were 1.613, 2.410 and 2.684 respectively. Uniformity indexes $\left(J^{\prime}\right)$ were $0.255,0.516$ and 0.748 . Diversity indexes $\left(H^{\prime}\right)$ were $0.910,1.995$ and 2.876. According to the evaluation criteria of community characteristic index, the higher the index value was, the more stable the community structure was [15], therefore, the water and sediment discharge regulation project had a positive effect on stabilization of zooplankton in the Yellow River estuary coastal waters. 

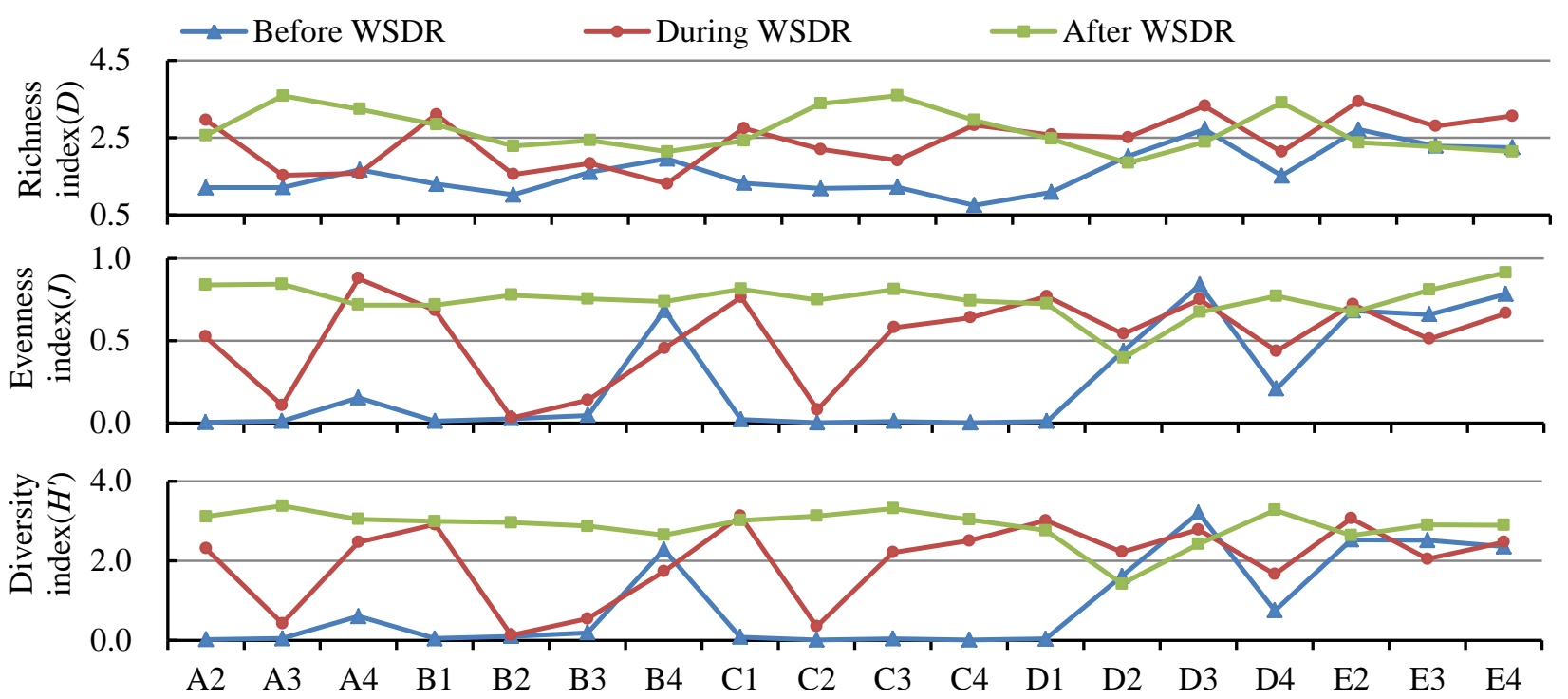

Figure 3. Zooplankton community indexes in the Yellow River estuary before and after the water and sediment discharge regulation (WSDR) project in 2014

Cluster Analysis. Systematic cluster was analyzed based on zooplankton abundance after taking logarithm. Community hierarchical clustering branches were constructed according to Bray-Curtis similarity coefficient. 18 stations involved in each survey were divided into three groups as sections similarly (Fig. 4). MDS pressure coefficients of the three cluster groups were $0.13,0.15$ and 0.15 respectively, the difference (One-Way ANOSIM) between each cluster group was highly significant $(\mathrm{P}<0.01)$. Therefore, three groups had reached an acceptable level of clustering.
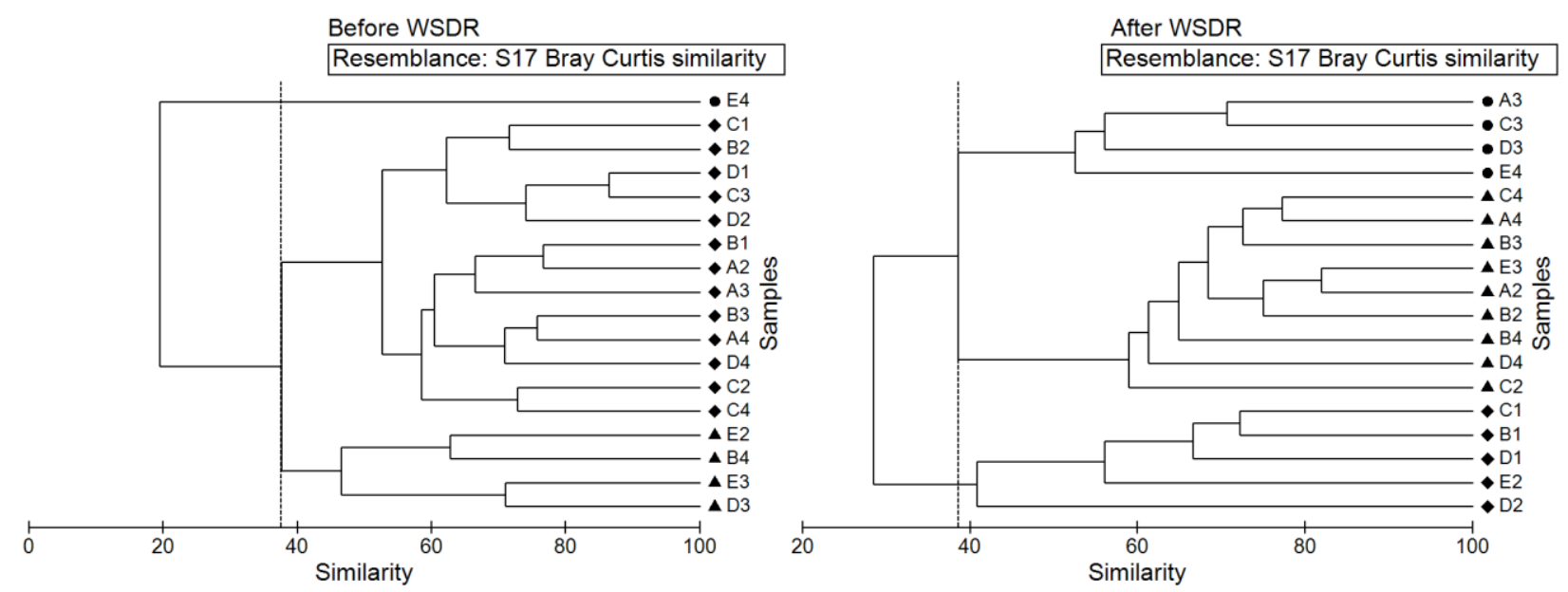

Figure 4. Plots of spatial cluster analysis based on different species abundance of zooplankton in the Yellow River estuary before and after the water and sediment discharge regulation (WSDR) project in 2014

Relation to Environmental Factors. By BIOENV analyzing, best combinations of environmental factors that affect the distribution of zooplankton abundance were shown in Table 1. Zooplankton distribution was mainly affected by phytoplankton abundance, water temperature, water depth, $\mathrm{pH}$, inorganic nitrogen concentration, active phosphate concentration and Chlorophyll a concentration before the water and sediment discharge regulation project, the correlation between the best combination and zooplankton distribution was significant $(\mathrm{P}<0.05)$. However, the best combination was composed by phytoplankton abundance, water depth and active phosphate concentration after the water and sediment discharge regulation project, with the maximum impact from phytoplankton abundance. 
Table 1 Best combinations of zooplankton abundance and environmental factors similarity matrices based on the Weighted Spearman rank correlation $(\rho)$ analysis

\begin{tabular}{ccccc}
\hline \multirow{2}{*}{ No. } & \multirow{2}{*}{ Environmental factors } & \multicolumn{3}{c}{ Correlation $(\rho)$} \\
\cline { 3 - 5 } & & Before WSDR & During WSDR & After WSDR \\
\hline 1 & phytoplankton & 0.190 & -0.039 & 0.425 \\
2 & swimming animals & -0.137 & -0.065 & -0.267 \\
3 & $\mathrm{DEP}$ & 0.013 & -0.091 & 0.039 \\
4 & $\mathrm{pH}$ & 0.129 & -0.120 & -0.037 \\
5 & $\mathrm{TEM}$ & 0.267 & -0.290 & 0.031 \\
6 & $\mathrm{SAL}$ & -0.125 & -0.148 & -0.145 \\
7 & $\mathrm{COD}$ & -0.223 & -0.093 & -0.073 \\
8 & $\mathrm{DO}$ & -0.079 & 0.112 & -0.100 \\
9 & $\mathrm{TN}$ & -0.150 & -0.176 & 0.102 \\
10 & $\mathrm{TP}$ & -0.142 & -0.008 & 0.005 \\
11 & $\mathrm{NO}_{2}-\mathrm{N}$ & -0.082 & 0.272 & -0.122 \\
12 & $\mathrm{NO}_{3}-\mathrm{N}$ & -0.087 & -0.124 & -0.122 \\
13 & $\mathrm{NH}^{4}-\mathrm{N}$ & -0.074 & 0.048 & -0.186 \\
14 & $\mathrm{SiO}_{4}-\mathrm{Si}$ & -0.188 & 0.172 & -0.211 \\
15 & $\mathrm{DIP}$ & 0.094 & 0.026 & 0.116 \\
16 & $\mathrm{Chl}$ & 0.067 & -0.220 & -0.085 \\
17 & $\mathrm{SS}$ & -0.054 & -0.281 & -0.083 \\
& $\mathrm{Best}$ & $0.515^{*}$ & 0.378 & 0.501 \\
& $\mathrm{Combination}$ & $(1,3-5,11,13,15,16)$ & $(1,3,11,14)$ & $(1,3,15)$ \\
\hline
\end{tabular}

* Related coefficient reached significant level $(P<0.05)$

\section{Conclusion}

Three surveys in the Yellow River estuary in 2014 showed that, environmental factors in the Yellow River estuary changed due to the injection of fresh water during the water and sediment discharge regulation project. Salinity and transparency reduced, while the concentration of suspended solids and nutrient increased. There was a large amount of zooplankton before the water and sediment discharge regulation project with the dense region located at coastal waters. The quantity of zooplankton reduced and the distribution was uniform relatively after the water and sediment discharge regulation project because the dominant Noctiluca miliaris disappeared. The water and sediment discharge regulation project had a positive effect on stabilization of zooplankton in the Yellow River estuary coastal waters. Zooplankton distribution between different stations was mainly affected by phytoplankton abundance, salty, water depth and the concentration of inorganic salts.

\section{Acknowledgements}

This paper was financially supported by the Special Scientific Research of National Marine Public Welfare Profession of China (Grant No.201405010).

\section{References}

[1] X.S. Jin and J.Y. Deng: Chinese Biodiversity, Vol. 8 (2000) No.1, p.65. (In Chinese)

[2] Q.Z. Yao, Z.G. Yu, T. Wang, H.T. Chen and T.Z. Mi: Environmental Science, Vol. 30 (2009) No.12, p.3534. (In Chinese)

[3] L. Zheng, Z.B. Lv, F. Li, L. Zhang and W.S. Yu: Journal of Fishery Sciences of China. , Vol. 21 (2014) No.3, p.602. (In Chinese) 
[4] Y.J. Liu, Z.B. Lv, F. Li, H.J. Zhang, Z.F. Xu and B.Q. Xu: Marine Fisheries, Vol. 34 (2011) No.3, p.316. (In Chinese)

[5] S.W. Li, Y. Zhang, F. Li and Z.B. Lv: Research of Environmental Sciences, Vol. 28 (2015) No.2, p.259. (In Chinese)

[6] W.C. Zhang, C.X. Zhang and T. Xiao: Advances in Earth Science, Vol. 24 (2009) No.11, p.1195. (In Chinese)

[7] W.J. Wang and G.X. Liu: Marine Science, Vol. 37 (2013) No.11, p.9. (In Chinese)

[8] R. Margalef: General Systems, (1958) No.3, p.36.

[9] J.L. Wilhm: Journal of Ecology, Vol. 49 (1968) No.1, p.153.

[10] R.V. Alatalo: Oikos, Vol. 37 (1981) No.2, p.199.

[11] H. Zhou, E. Hua and Z.N. Zhang: Periodical of Ocean University of China, Vol. 40 (2010) No.8, p.80. (In Chinese)

[12] Y.Z.Qi, Red Tides in Coastal China. (Beijing: Scientific Press, China 2003)

[13] T.W. Zhang, L.Y. Zhu, P.P. Xu, H. Zhou and B.J. Qi: Periodical of Ocean University of China, Vol. 39 (2009) No. Sup, p.89. (In Chinese)

[14] Q. Gao, Z.L. Xu and P. Zhuang: Chinese Journal of Oceanology and Limnology, Vol. 26 (2008) No.2, p.178. (In Chinese)

[15] W.S. Gao, X.B. Liu, Q.F. Zhang, Y.S. Xu, Y.Y. Ma, R. He and Y. Liu: Marine Science, Vol. 38 (2014) No.4, p.55. (In Chinese) 